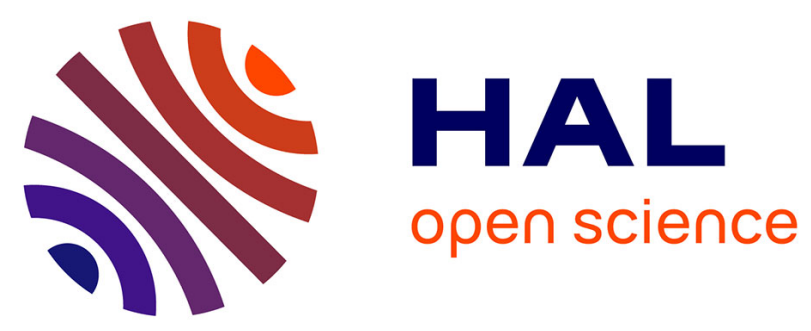

\title{
Reed warblers in the Marquesas Islands: song divergence and plumage convergence of two distinct lineages
}

\author{
Alice Cibois, Jean-Claude Thibault, Nicholas Friedman, Kevin E Omland, \\ Laure Desutter-Grandcolas, Tony Robillard, Eric Pasquet
}

\section{- To cite this version:}

Alice Cibois, Jean-Claude Thibault, Nicholas Friedman, Kevin E Omland, Laure Desutter-Grandcolas, et al.. Reed warblers in the Marquesas Islands: song divergence and plumage convergence of two distinct lineages. Emu, 2019, 119 (3), pp.251-263. 10.1080/01584197.2019.1597633 . hal-02626269

\section{HAL Id: hal-02626269 \\ https://hal.science/hal-02626269}

Submitted on 26 May 2020

HAL is a multi-disciplinary open access archive for the deposit and dissemination of scientific research documents, whether they are published or not. The documents may come from teaching and research institutions in France or abroad, or from public or private research centers.
L'archive ouverte pluridisciplinaire HAL, est destinée au dépôt et à la diffusion de documents scientifiques de niveau recherche, publiés ou non, émanant des établissements d'enseignement et de recherche français ou étrangers, des laboratoires publics ou privés. 
Reed warblers in the Marquesas Islands: song divergence and plumage convergence of two distinct lineages

Alice Cibois ${ }^{\mathrm{A}, \mathrm{E}}$, Jean-Claude Thibault ${ }^{\mathrm{B}}$, Nicholas R. Friedman ${ }^{\mathrm{C}, \mathrm{D}}$, Kevin E. Omland ${ }^{\mathrm{C}}$, Laure DesutterGrandcolas $^{\mathrm{B}}$, Tony Robillard ${ }^{\mathrm{B}}$, and Eric Pasquet ${ }^{\mathrm{B}}$

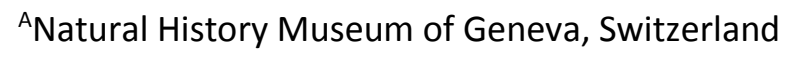

${ }^{B}$ Institut Systématique, Evolution, Biodiversité (ISYEB), Muséum National d'Histoire Naturelle, CNRS, Sorbonne Université, EPHE, Paris, France

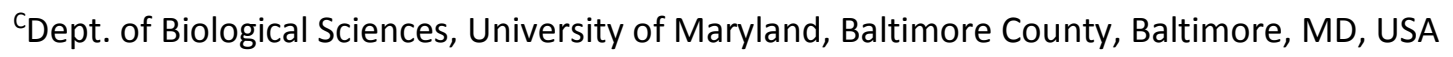

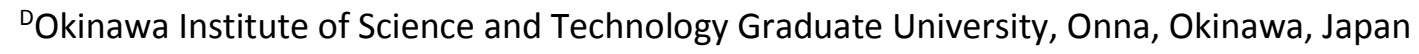

ECorresponding author. Email: Alice.Cibois@ville-ge.ch

\section{Abstract}

The Pacific Ocean is the site of the most important diversification of insular reed warblers (Acrocephalus). In the Marquesas Islands (Eastern Polynesia), reed warblers belong to two distinct lineages that have reached the archipelago independently. We used mitochondrial sequences and microsatellite markers and found evidence of gene flow between the two lineages. One island in particular, Nuku Hiva, seems to act as the main contact zone between the two taxa. We then used reflectance spectrometry to evaluate the variation of carotenoid colouration among all populations. The Marquesan reed warblers exhibit convergent evolution in carotenoid-based plumage colouration, but variation among islands was important. Having two different phylogenetic origins, the two lineages acquired their yellow colour independently and there is stochastic variation in 
plumage among islands. Finally, we analysed the songs of reed warblers from the main islands. The multifactorial analysis showed that vocalizations of the Marquesan reed warblers differ slightly between species, significant differences between islands leading to different dialects. Vocal characteristics may act as the main pre-zygotic barriers when birds from different lineages come into contact. This study provides another example of convergence in plumage evolution in insular bird species. Furthermore, it highlights the importance of integrative analyses, using both genetic and phenotypical characters, for the study of the evolutionary history of the Pacific Ocean avifauna.

\section{Keywords}

Acrocephalidae, plumage colouration, convergent evolution, vocalization, island evolution, microsatellites, mtDNA, Oceania.

\section{Introduction}

The Acrocephalidae represent a morphologically conserved family within the Old World warblers (Fregin et al. 2009; Alström et al. 2013). Most species have nondescript plumage, with dull brownish or greyish upperparts and whitish to bright yellow underparts, a few species showing supercilium, crown stripe, or streaks (Kennerley and Pearson 2010). Having 6 genera and 61 species (Gill and Donsker 2018), they reach their highest species richness in western central Asia and Africa. Reed warblers forage primarily on insects and in the temperate regions most reed warblers are migratory. Around one-third of the species are found on oceanic islands, often very far away from continental land masses, where they have become sedentary endemics. On most of these tropical or subtropical islands, acrocephalids occupy completely different habitats from those occupied by their continental relatives. Although wetlands are used when available, most species are found in woodland, dry bush or scrub (Leisler and Schulze-Hagen 2011; Bell 2018). 
Having 20 endemic species, the Pacific Ocean represents the most important diversification of insular acrocephalids, all in the genus Acrocephalus. They have a disjunct distribution, as they are found discontinuously from Micronesia to the Pitcairn group and Hawaii (only small islands with shrubland), but are absent from the large and species-rich islands in southern Melanesia and central Polynesia (for instance Vanuatu, Fiji, Samoa). The Pacific reed warblers are able to thrive on very small and isolated islands, where resources are sparse, an ability that is consistent with part of the supertramp definition (Diamond 1974). They are often the only land bird on low-lying atolls. However, they also have notably long lifespans and are territorial, living in pairs or trios (Mosher 2006; Thibault and Cibois 2017).

Molecular phylogenies provide evidence for a complex pattern of colonization of the Pacific by reed warblers, in which most lineages are much younger than the ages of the islands they occupy (Fregin et al. 2009; Cibois et al. 2011). The Pacific reed warblers are divided into two main clades (supplemental Figure S1). The first includes all species from Micronesia (except Guam), Australia (colonized from an insular ancestor, thus a case of reverse colonization), and two Polynesian taxa from the Line Islands and the southern Marquesas. The second lineage includes all remaining Eastern Polynesian taxa and the Hawaiian species. The taxa endemic to three archipelagos (Mariana, Marquesas and Society Islands) are polyphyletic, suggesting several independent colonization events (Cibois et al. 2007; Cibois et al. 2008; Saitoh et al. 2012). Overall, the colonization of reed-warblers in the Pacific has been very rapid within the last two million years and it did not follow a regular, stepping-stone-like pattern, as distribution solely might have suggested.

Leisler and Winkler (2015) analysed the morphological variation among insular and continental species and found general evidence of convergent evolution of stronger legs, shorter rictal bristles and broader and rounder wings on islands compared to continental taxa. Their results contrast with those of Komdeur et al. (2004), who found no flight differences between the Seychelles Warbler (Acrocephalus sechellensis) and three species that are migratory but do not migrate long-distances. 
They concluded that the Seychelles Warbler may have a behavioural reluctance to cross open seawater rather than a morphological impediment. It is likely that the conclusions of these two different studies are both true within the large insular reed warbler radiation: the original colonizers must have good capacities to sustain over-water dispersal, even if those were facilitated by rare events like hurricanes. But during this oceanic radiation, the reed warblers have also developed behavioural adaptations to their new local environment: often a wider prey spectrum, a more terrestrial niche, or a different social system, and this has led to many idiosyncrasies that often differ between archipelagos. Thus, global rules, as proposed when studying the evolution of insular birds, often do not fit the evolution of reed warblers in the Pacific.

The most puzzling example of complex colonization pattern is found in the Marquesas Islands, which have two distinct lineages, one in the north and another in the south (Cibois et al. 2007). The Northern Marquesan Reed Warbler (Acrocephalus percernis) is closely related to Polynesian species from the Tuamotu and Gambier Islands, whereas the Southern Marquesan Reed Warbler (Acrocephalus mendanae) is closely related to Micronesian taxa (from Nauru and Pagan). Despite their distinct origin, both reached the Marquesas at roughly the same time, around 0.6 million years ago (Mya) according to a mitochondrial molecular clock. The two taxa are cryptic in the sense that they were considered a single species on the basis of plumage similarities - both are relatively large birds, with bright yellow underparts, olive upperparts (Kennerley and Pearson 2010). Furthermore, that this archipelago is so remote led Murphy and Mathews (1928) and all subsequent ornithologists to assume they would have been monophyletic.

In addition to the molecular phylogeny, Cibois et al. (2007) studied the morphology of these two species using multivariate analyses. Overall there is a large overlap in morphometrics, although on average the southern taxon is larger than the northern one. The analyses also suggested a higher influence of resource availability than of phylogeny on the morphology of the Marquesan reed warblers: birds on dry and smaller islands tend to be smaller than birds on large islands, irrespective 
of their phylogenetic origin. These first genetic and morphological studies, however, left unresolved several issues regarding the evolution of these two taxa. First, the molecular phylogeny was based solely on mitochondrial genes and a limited number of individuals (26, covering all subspecies and 2 to 5 individuals per island). Our first objectives were then to increase the sampling and to include a combination of mitochondrial and nuclear markers. As trials with nuclear intron sequences revealed no variation between these two recently diverged groups, we chose hypervariable microsatellite markers that have been previously used to decipher the phylogeography of insular populations of reed warblers (Richardson et al. 2000; Cibois et al. 2010). Second, while previous ornithologists have noted plumage in these groups as being similar, qualitative comparisons performed by human observers can in some cases mislead (Eaton and Johnson 2007). To investigate the colouration of the two Marquesas reed warblers in a more objective way, we used reflectance spectrometry to evaluate the variation of carotenoid colouration among all populations. Finally, we measured and compared vocalizations, which are known as major prezygotic barriers in many closely related passerine species, in particular among species with similar plumages, like in Acrocephalus (Lemaire 1977) or Phylloscopus (Martens et al. 2008). Marquesan reed warblers are known to produce a combination of whistles and rasping sounds that includes many repetitions of particular motifs (Kennerley and Pearson 2010). Subtle differences between the different subspecies have been noted, but not all islands were sampled for sounds and individual variation was not assessed (MacPherson 1998).

Thus, our first goal in this study is to test whether gene flow occurs between the two taxa, and additionally within each of the island groups. We then evaluate within this system two main mechanisms known to play a role in bird species recognition, based on visual and vocal characters. Globally insular birds are expected to have colour that is less elaborate than their continental counterparts (Doutrelant et al. 2016), though in the Passeriformes there are many exceptions to this rule. The Marquesan reed warblers have yellow underparts that are brighter than most continental Acrocephalus (Bell 2018). This may be explained by convergent evolution, which occurs frequently in insular species (Warren et al. 2005; Jones and Kennedy 2008). This convergence might have been 
favoured by environmental factors over the signal divergence that is expected to be less important in allopatric species than in sympatric taxa (Martin et al. 2010). Regarding vocalization, if gene flow between islands is low, dialects are expected to develop over time by cultural drift or adaptation (Potvin and Clegg 2015). But because the two Marquesan reed warblers have diverged relatively recently, we might expect to identify differences in vocalization that could play a role in species recognition, particularly if gene flow occurs between the two taxa.

\section{Methods}

\section{Genetics}

From 2000 to 2010, we mist-netted and sampled 135 reed-warblers in the nine Marquesas islands (supplemental Figure S1). We used playback of recorded songs to lure birds into nets. Because reedwarbler males are strongly territorial, most birds captured were males (recognized as singing individuals). We avoided recapture by marking the forehead of captured birds with biodegradable paint and the locations of all singing individuals were geo-referenced. Additionally, we used toe pads from 11 specimens collected by the Whitney South Sea Expedition in the American Museum of Natural History (AMNH), in New York (for a summary of this expedition, see Thibault and Cibois (2017)). These toe pads were sampled for a previous study (Cibois et al. 2007).

Genomic DNA was extracted, amplified and sequenced using standard protocols, as in Cibois et al. (2007). We amplified and sequenced a portion of the mitochondrial cytochrome $b$ gene with the primers 43L/17H (879 bp) (Edwards et al. 1991; Cibois et al. 2007). Contigs were assembled using Sequencher (Genecodes, Ann Arbor, Michigan). All sequences were deposited in GenBank (accession numbers MK517292-MK517409; Table S1). For the mitochondrial data, number of haplotypes, nucleotide diversity and mismatch distributions were calculated using DnaSP 6.12.01 (Rozas et al. 2017). Haplotype networks were constructed using Network 5.0.0.3 (Bandelt et al. 1999). Signals of 
population expansion were tested using Harpending's raggedness index $r$ (Schneider and Excoffier 1999) using Arlequin 3.1 (Excoffier et al. 2005). We also used Fu's Fs and Tajima's D to test for selective neutrality and population equilibrium (Tajima 1989) using DnaSP. The $\Theta_{\text {ST }}$ values between pairs of population were calculated in Arlequin (sequential Bonferroni corrections were applied when appropriate). For the calculation of the pairwise permutations, the individuals from Hatutaa were included into the Eiao population, and the individuals sampled in Mohotani were included into the Hiva Oa group.

We genotyped six microsatellite loci originally developed for the Seychelles Warbler: Ase12, Ase13, Ase18, Ase34, Ase51, Ase55 (Richardson et al. 2000). Microsatellite fragments were amplified using a touch-down PCR as described in the original publication. Genotyping was conducted on a 310 Genetic Analyzer (Applied Biosystem) using multiplex PCR (Qiagen). Results were visualized using Genescan Analysis 3.1.2 (Applied Biosystems). The genetic diversity was quantified for allelic richness, observed heterozygosity and expected heterozygosity. These statistics were estimated using Arlequin, Fstat 2.9.3.2 (Goudet 1995) and MSA (Dieringer and Schötterer 2003). Deviations from Hardy-Weinberg genotype frequency equilibrium were tested with Arlequin (10 000 permutations). The $\mathrm{F}_{S \mathrm{ST}}$ values between pairs of populations were calculated in Arlequin (sequential Bonferroni corrections were applied when appropriate). For the calculation of the pairwise permutations, the individuals from Hatutaa were included into the Eiao population, and the individuals sampled in Mohotani were included into the Hiva Oa group.

Bayesian assignment of individuals to clusters without using prior information of the sampling locations was conducted using Structure 2.3.1 (Pritchard et al. 2000) and the microsatellite data. The inferred number of clusters, $K$, was tested from $K=1$ to $K=10$. Each run was pursued for 1000000 iterations, with a burnin period of 100 000. A correlated allele frequency and admixture model was used. Convergence was assessed with ten independent runs. The inferred number of clusters K was estimated using the value of $\mathrm{K}$ with the highest probability: posterior probabilities were computed as 
172 indicated in Pritchard et al. (2000), and an additional ad hoc statistic ( $\Delta K$ ) was also estimated,

173 following the simulation study of Evanno et al. (2005). We estimated the number of immigrants per

174 generation using Migrate 3.6 (Beerli 2009), which follows a MCMC-based maximum-likelihood

175 approach based on an expansion of the coalescence model (from present to the most recent

176 common ancestor). The runs consisted of 10 short chains (sampling 10000 trees) and three long

177 chains (sampling 100000 trees) with a burn in period of 10000 trees. All runs were repeated five

178 times to verify consistency of results. To avoid applying a unique mutation rate to the microsatellite

179 loci, we inferred the number of immigrants per generation Ni by multiplying the mutation-scaled

180 effective population size $\Theta$ to the mutation-scaled effective immigration rate $\mathrm{M}$.

181 Finally, for both data sets, we tested the hypothesis of Isolation by distance (IBD) among island

182 groups using a Mantel test between the genetic distances (estimated as OST/(1- OST) for mtDNA and

183 Fst /(1-Fst) for microsatellites) and the logarithm of geographic distances (Rousset 1997).

\section{Plumage colouration}

We assessed the carotenoid-based colouration of Marquesan reed warblers using reflectance

spectrometry, a method used to quantify colour independently of the spectral sensitivity of the birds

189 (Andersson and Prager 2006). We followed the techniques used in previous studies of plumage

190 colouration of several groups of Passeriformes (Hofmann et al. 2006; Kiere et al. 2007). Plumage colour was measured using an Ocean Optics USB 2000 spectrometer, with a full spectrum Xenon light source (Ocean Optics PX-2). Measurements were calibrated by a dark and a Spectralon diffuse white standard (Labsphere, North Sutton, New Hampshire). We worked on specimens collected during the Whitney South Sea Expedition and held at the American Museum Natural History collection. We 
the bright yellow underparts of the birds; we measured three regions, throat, breast, and lower belly, which correspond to the visible gradation from more intense on the throat to less intense on the lower belly. The plumage regions followed the topography provided by Andersson and Prager (2006). We took three non-overlapping measurements of each region, perpendicular to the plumage surface, and we calculated the mean of the three measures. Initially we also measured the colour of the nape. However, as preliminary analyses showed that the colour of this area was too patchy and gave a large standard deviation between hue values, this region was removed from further analyses.

The evaluation of the colour space was based on three characters: hue, saturation and brightness. Hue was estimated by the reflectance midpoint within the visible spectral range $(400-700 \mathrm{~nm}$, not including the UV peak between 300 and $400 \mathrm{~nm}$ ), which is a commonly used measure for carotenoidbased plumage (Friedman et al. 2011). Saturation, or chroma, corresponds to our perception of the richness of a hue. In the Marquesan reed warblers, the most pronounced colour is yellow (500-600 $\mathrm{nm}$ ) and so we measured the saturation of this colour as the reflectance from $500-600 \mathrm{~nm}$ divided by the overall reflectance $(300-700 \mathrm{~nm}$ ) and multiplied by 100 (i.e., yellow chroma, the percentage of the feather's reflectance curve in the yellow part of the spectrum; Montgomerie 2006). Brightness was measured as the mean reflectance over the spectral range $(300-700 \mathrm{~nm})$. We compared Marquesan reed warblers with another bright yellow species, the Tahiti Reed Warbler (Acrocephalus caffer). We tested the significance of variances between taxa and populations using Multivariate analysis of variance (MANOVA and nested MANOVA, using the Pillai test for significance; Pillai 1955). We used linear discriminant analysis (LDA), first to infer which of the colour variables we measured were the most discriminant between populations. Second, we compared two discriminant functions: (1) habitat richness in terms of vegetation diversity, in which the islands are classified either as "rich" with more than 100 indigenous plants or "poor" with less than 100 plant species (due to its proximity to the large Hiva Oa, Tahuata is classified as "rich" as well), and (2) phylogeny, in which the islands are classified according to the two clades, Northern or Southern. All analyses were conducted using 
the packages ggplot2, Mass, and devtools in R (R-Core-Team 2017), with the data standardized with the scale function (zero mean and unit variance).

\section{Vocalization}

Between 1987 and 2012, we recorded males of each Marquesan population, using a Sony ECM 929LT condenser microphone and a Sony WM D6C tape recorder. Tapes were digitized at the Muséum national d'Histoire naturelle, Paris (MNHN, ISYEB) and sounds were deposited in the Sound Library of the MNHN (Accession numbers MNHN-SO-2019-32 to MNHN-SO-2019-59). For the analysis, we selected 4 males from each population (except Hatutaa and Mohotani). We used both short and long songs, but not the alarm calls. Sonograms were generated and a song analysis was performed using Avisoft-SASLab Pro 5.2.07 (Avisoft Bioacoustics). For each individual, up to 5 sequences of 4 seconds continuous vocalization were selected. In our study, we separate two different components of the songs, hereafter called syllables: the "whistle" (shown as horizontal or curved lines in sonograms, see Figure 3) and the "rasping" (shown as multiple blurring lines in sonograms, see Figure 3). In each sequence, we measured the number of syllables, the type of syllable (whistle or rasping), and the number of time the whistle or rasping was repeated. For each syllable we measured duration, start frequency, end frequency, peak frequency, maximum frequency, and minimum frequency (examples for these measures can be seen on this webpage https://www.avisoft.com/tutorial_measure3.htm). Mean values of these parameters over all sequences were computed for each individual. We tested the significance of variances between taxa and populations using Multivariate analysis of variance (MANOVA and nested MANOVA, using the Pillai test for significance), and linear discriminant analysis to infer which of the variables were the most discriminant between populations. As in the analysis of plumage colouration, we also compared two discriminant functions, "habitat richness" and "phylogeny" (see above). 


\section{Genetics}

28 haplotypes were found in the mitochondrial sequences of over 143 individuals, global haplotype diversity $(\mathrm{Hd})$ and nucleotide diversity $(\mathrm{Pi})$ being 0.92 and 0.34 , respectively. The lowest genetic diversity was found in Ua Pou (Hd 0.43 and Pi 0.01) and the highest in Nuku Hiva (Hd 0.72 and Pi 0.11). We compared haplotype diversity and island area and we found no significant relationship $\left(R^{2}\right.$ $=0.2379, p=0.2669$, supplemental Figure S2). The haplotypes were divided into two main groups, separated by 6 base pairs that corresponded to the two taxa. We found 15 haplotypes for $A$. percernis (Hd 084, nucleotide diversity Pi 0.09, Figure $1 \mathrm{a}$ ) and 13 haplotypes for $\mathrm{A}$. mendanae ( $\mathrm{Hd}$ 085, nucleotide diversity Pi 0.09, Figure 1b). A single individual from Nuku Hiva (A. percernis), Nuku20, had a haplotype from the Southern group that was otherwise found only in individuals from Ua Pou. This individual was identified as male in the field, and its sex was later confirmed with the P2/P8 set of primers used for PCR-based sexing in birds (Griffiths et al. 1998). Mismatch distributions for each taxon were multimodal (Figure 1), indicating historically stable populations, Fu's Fs (South 1.34, North -0.41) and Tajima's D (South 1.14, North 0.40) being non-significant. Harpending's raggedness index was significant for South $(r=0.097, \mathrm{P}<0.05)$ and close to significant for North $(r=0.074, P<0.10)$, indicating a poor fit of the observed and expected mismatch distributions. Global $\Theta_{\text {ST }}$ was high (0.69; 95\% confidence interval 0.59-0.79), and pairwise $\Theta_{S T}$ indicated significant genetic structure between all pairs of islands, except between two pairs of close islands (Hiva OaMohotani/Tahuata, Eiao-Hatutaa/Nuku Hiva). The Mantel test was significant for South $(p=0.0389)$ but not for North $(p=0.1696)$, suggesting that some isolation by distance might be prevalent for the mitochondrial haplotypes only in the Southern part of the archipelago (the most isolated islands, Ua Pou and Fatu Iva, also have the most divergent sequences).

The allelic richness of the six microsatellite loci varied from 1.04 to 3.36 (Table S2). Deviation from HWE ( $\alpha=0.05$ ) was found in two cases (Nuku Hiva for locus 1, Hiva Oa for Locus 3 ), but null allele 
frequency estimated by FreeNa for these loci and populations were less than or equal to 0.2 , suggesting that null alleles were uncommon to rare in our dataset. Pairwise $\mathrm{F}_{\mathrm{ST}}$ values averaged over the six loci were high $(0.28 ; 95 \%$ confidence interval $0.22-0.36)$, and these values indicated significant genetic structure between all pairs of islands except two different pairs of islands (Fatu Iva/Ua Pou and Hiva Oa-Mohotani /Tahuata). The Mantel test between genetic and geographic distances was not significant for either of the two island groups ( $p=0.5028$ and 0.4956 for South and North, respectively). Bayesian clustering analysis revealed $\mathrm{K}=4$ as the best estimate for the number of clusters among Marquesan reed-warblers (Figure 2). The first cluster (in blue) corresponds mainly to individuals from three northern islands (Eiao, Hatutaa, Nuku Hiva), the second cluster (in green) corresponds to individuals from Ua Huka, the third (yellow) and fourth (red) correspond to a mixture of individuals from the five southern islands (Fatu Iva, Hiva Oa, Mohotani, Tahuata and Ua Pou). The two first clusters correspond mainly to A. percernis, the two others to A. mendanae.

Admixture was lowest in Ua Huka (100\% of individuals in cluster 2 ) and highest in Ua Pou (33\% of the individuals could not be attributed to a single cluster). Several individuals were classified in a cluster that does not correspond to their taxon: six individuals from Nuku Hiva (A. percernis) were classified in the yellow or red "Southern" clusters (but not Nuku20, the male with a mitochondrial haplotype from Ua Pou) and five individuals from Fatu Iva and Mohotani ( $A$. mendanae) were classified in the green "Northern" cluster. Migrate results suggested gene flow between the two groups with a migration rate larger from the Southern islands group $(m=6.64)$ than on the opposite direction $(m=2.44)$

\section{Plumage colouration}

Colour measurements (means and standard deviations) are provided on Table S3. Values of hue, chroma and brightness correspond to the general gradation observed on the underparts of all individuals, from a more saturated yellow on the throat to less bright and less saturated yellow on 
the lower belly. Overall the Tahiti Reed Warbler A. caffer is less yellow than the Marquesan reed warblers: A. caffer and A. percernis differed significantly in the degree of saturation of yellow in the breast (MANOVA's Pillai test $\mathrm{P}<0.001$ ) and in the throat $(\mathrm{P}<0.01) ; A$. caffer and $A$. mendanae also differed in the degree of saturation of yellow in the breast $(P<0.001)$ and in the throat $(P<0.01)$. Finally, they differed in the value of hue in the throat $(P<0.01)$ and lower belly $(P<0.01)$.

Within the Marquesan reed warblers, the colour measurements differed significantly when the two species are compared and all variables considered $(P<0.05$, Table 1$)$, the only significant difference being the hue of the throat $(P<0.01)$. However, the nested MANOVA revealed that the variation among populations within taxa was more important than the variance between taxa, only six variables having significant differences, including the hue of the throat (Table 1). It is likely that the significance of this variable between taxa was due to the large variation observed among populations. This assumption was confirmed by the results of the LDA, in which the confidence ellipses of the two taxa overlapped almost completely in the projection of the two first axes (supplemental Figure S3).

When the two taxa are analysed separately, the LDA coefficients revealed that in A. mendanae, the saturation and the hue of the throat were the most discriminant factors in the first axis, and the saturation and hue of the lower belly were the most discriminant factors for the second axis (supplemental Figure S4). In this taxon, the population from Ua Pou was the most divergent, having intense yellow in all its underparts (highest values of saturation, see supplemental Table S3), whereas the birds from Fatu Iva exhibited the highest values of hue (throat, breast and lower belly).

In A. percernis, the hue of the breast and of the lower belly were the strongly explanatory factors in the first axis, variables from the breast being important in the second axis (supplemental Figure S5). The population on Hatutaa, the smallest and driest island of the archipelago, was the most divergent in the LDA, having a light brownish yellow (high values for hue and low values for brightness, see supplemental Table S3). Results of the LDA for the two different predictive functions were significant 
$(P<0.05)$, but both functions misclassified almost one third of the individuals $(27.19 \%$ individuals misclassified with "Habitat richness", and 25.43\% with "Phylogeny"). This suggests that none of these predictive functions described accurately the variation observed in the plumage colouration in the Marquesan reed warblers.

\section{Vocalizations}

Vocalization characteristics of the Marquesan reed warblers are given in supplemental Table S4. The Marquesan reed warblers provide complex and diverse vocalizations, having 13 to 21 different syllables within a 4 second interval. The repetition of similar motifs was found in all individuals, although in different proportions. On average, individuals from Ua Pou used the highest number of repetitions (3.6 repetitions during 4 seconds recording, see an example in supplemental Figure S6), whereas the lowest numbers of repetitions (less than 1 during 4 seconds recording, on average) were found for two individuals from Ua Huka and one bird from Tahuata. The ratio of whistle and rasping syllables varied from $70 \%$ of whistle on Tahuata to $66 \%$ of rasping on Ua Huka. The vocalization measurements differed significantly when the two species were compared and all variables considered $(P<0.001$, Table 2$)$, significant difference being only for two variables, number of repetitions and proportion of whistles (both with $\mathrm{P}<0.01$ ). The variation among populations within taxa is also significant when all variables are considered $(P<0.01)$, and four variables were also significant individually (number of syllables, number of repetitions, proportion of whistles, and duration).

Overall, the two taxa differ in their vocalizations and there was little overlap in the LDA space, but the variation between islands was substantial (Figure 3). The LDA coefficients revealed that the proportion of whistles and the start frequency were the most discriminant factors in the first axis, and the number of repetitions and the end frequency were the most discriminant factors for the second axis. Results of the LDA for the two different predictive functions were significant $(P<0.05)$, 
and both functions classified correctly almost all individuals, "Phylogeny" (3.6\% of misclassified individuals) being a better predictive function than "Habitat Richness" (7.1\% misclassified individuals). This suggests that despite the differences in song characteristics observed between islands, the vocalizations of Marquesan reed warblers have kept patterns that correspond to each of the two lineages.

\section{Discussion}

\section{Gene flow between lineages}

Gene flow among avian species is not a rare phenomenon, particularly in passerines (Ottenburghs et al. 2015). This is even more apparent when studying closely related species, or groups of recently diverged species, as gene flow often occurs during speciation (Nosil 2008; Mallet et al. 2016). For instance, Reifová et al. (2016) showed that interspecific gene flow occurred during the Acrocephalus radiation, and not only between sister species. Here we found evidence of gene flow between $A$. percernis and A. mendanae, two species that inhabit distinct but close island groups in the Pacific Ocean, with a different phylogenetic origin. One island in particular, Nuku Hiva, seems to act as the main contact zone between the two taxa. The only individual with a conflicting mitochondrial genotype (out of 143 sequences) was caught on this island, and six other individuals showed evidence of admixture from Southern nuclear markers. This island is one of the largest in the archipelago, with $380 \mathrm{~km}^{2}$ and a summit at 1,227 m. Its reed warbler population is the largest today in the Marquesas (Thibault and Cibois 2017). Its large coastline and high mountains might have facilitated the arrival of birds from other islands. Interestingly, the asymmetry of gene flow between the two taxa, more important from South to North than in the opposite direction, is consistent with the current prevailing winds that blow from the southeast below the equator (Galzin et al. 2016). 
In terms of plumage, birds from Nuku Hiva cannot be distinguished from the Eiao population (supplemental Figure S5). The non-admixed individuals from Nuku Hiva are identical to the Eiao/Hatutaa birds for nuclear markers (cluster blue in Figure 2); these three islands also share mitochondrial haplotypes (Figure 1). But despite their genetic relatedness, the birds from Hatutaa exhibit distinct plumage, having a light brownish yellow (high values for hue and low values for brightness). On the other hand, the distinctiveness of birds from Ua Huka based on molecular markers (original haplotypes in Figure 1 and the yellow cluster in Figure 2) was not reflected in comparisons of their plumage (see their large overlap in the PCA space in supplemental Figure S5). These examples highlight the overall discrepancy between genetic and plumage characters found in the Marquesan reed warblers. Additionally, island size and distance between islands seemed to have little influence on the observed genetic diversity.

\section{Convergence in Plumage Colouration}

Both species have strong yellow colouration, especially in the underparts. A. mendanae does not share this colour with its closest related species as it belongs to a group of brown reed warblers ranging from Line Islands up to Australia and Saipan in the Mariana Islands (the "Micronesian Clade" in Cibois et al. 's (2011) tree; see supplemental Figure S1). On the other hand, A. percernis belongs to a group of mostly grey or brown species from the Cook Islands to Hawaii (the "Polynesian Clade"; supplemental Figure S1) that includes also a few species with yellow colouration, mostly found in the Society islands, the brightest being the Tahiti Reed Warbler. We showed that, in terms of plumage colouration, the two Marquesan reed warblers are more similar to each other than either is to the Tahiti Reed Warbler. Reflectance spectrometry measures demonstrate that they share similar carotenoid-based plumage colouration, but local variation (i.e. among islands) is important. This variation is not correlated to the habitat diversity of the islands. In contrast, size is influenced by resource availability: reed warblers on dry and smaller islands tend to be smaller than birds on large 
islands, irrespective of their phylogenetic origin (Cibois et al. 2007; Leisler and Winkler 2015). Having two different phylogenetic origins, the two Marquesan reed warbler lineages acquired their yellow colour independently but show stochastic variation in plumage among islands.

The evolution of convergent plumage colour often implicates selection, as suggested for melanistic insular flycatchers (Uy and Vargas-Castro 2015; Uy et al. 2019) or in sexual dichromatism for Petroica robins (Kearns et al. 2015). Many correlations between melanistic plumages and traits under selection have been suggested, for instance aggressiveness (Ducrest et al. 2008), immunity (Gangoso et al. 2011), or for the melanic form of the Tahiti Reed Warbler, camouflage in dark understories (Cibois et al. 2012). Similarly, carotenoid compounds can be under selection during speciation (mostly sexual selection for colouration) and they also have important roles in vision (von Lintig 2012), as antioxidants (Fiedor and Burda 2014), or in the immune system (Sepp et al. 2011).

Several hypotheses could thus be proposed to explain colour variation in the Marquesan reed warblers system, involving the source of carotenoid, selection on the deposition of this pigment on the plumage, or a combination of the two. The diet of the Marquesan reed warblers is known to be rather eclectic, including mainly insects but also small vertebrates (some of them introduced), fruits and seeds (Leisler and Schulze-Hagen 2011; pers. obs.). The level of endemicity of insects and plants is high in the archipelago (Lorence et al. 2016; Roderick and Gillespie 2016), so one can wonder whether the "Marquesan yellow" pigment could be specific to an endemic prey or plant. An analysis of debris found in feces might improve our knowledge of the diet of these birds (Ramage et al. in prep.).

Native predators (raptors, mammals, snakes) are all absent from the archipelago, so predation is probably not a leading factor in the Marquesan reed warbler system. Interspecific competition can impact trait evolution such as by character displacement in closely related species (Pfennig and Pfennig 2012). In the Marquesas Islands, competition might have been more important in the past before the extinction of several terrestrial birds (Thibault and Cibois 2017). However, most of these 
were parakeets and pigeons and their frugivorous diet would have only marginally overlapped with that of the reed warblers. The monarch flycatchers are the only other native insectivorous passerines in the Marquesas Islands. They are forest-dwelling birds, found in both dry and wet forests, whereas reed warblers prefer today dry scrub habitats and avoid humid forests. However, we note that most of the littoral and low altitude habitats have been highly modified in the archipelago, only relictual native xerophylous forests remaining (Lorence et al. 2016). It is difficult to evaluate how much space was shared between monarchs and reed warblers in the past. Thus, we suggest that sexual selection and pleiotropic effects, rather than predation and competition, have been the drivers of colour divergence of these birds. Alternatively, plumage colour variation can be an adaptive response to variation in light environments across habitats (McNaught and Owens 2002) and similar light environments might have influenced the convergent plumage evolution of reed warblers in the Marquesas. Analysis of whole genomes, however, would be necessary to explore the genetic basis and the evolutionary processes that mediate convergent plumage colouration in the Marquesan reed warblers, like recent studies on Holarctic redpoll finches (Mason and Taylor 2015) or Eurasian crows (Poelstra et al. 2014).

\section{Vocalizations}

Fiedler (2011) showed that song characteristics in the Acrocephalidae are heavily influenced both by phylogeny and natural history. For example, males of migratory species have larger repertoires than tropical, sedentary species, and often include more mimicry. While a single species from the Pacific Ocean was included in Fiedler's study (the Australian Reed Warbler Acrocephalus australis), Leisler and Schulze-Hagen (2011) used her work, along with isolated observations, to infer that insular species have in general simpler and shorter songs than continental species. Although examples of simpler, almost call-like songs have been reported in two Polynesian species [Henderson Reed Warbler A. taiti; (Graves 1992); and Rimatara Reed Warbler A. rimitarae; (Thibault and Cibois 2006)], 
the global pattern is probably more complex and idiosyncratic. For instance, Bell's (2018) analysis of numerous Pacific Acrocephalus showed that the mean frequency of song syllables was inversely correlated with mean body size. He also suggested that the environment though which the sound is transmitted also influences the song, lower frequencies being prevalent in forest and scrub habitats.

Although a comparison of the complexity of Marquesan reed warblers' songs with continental species was beyond the objectives of this study, we noticed that the Marquesan reed warblers provide long and complex vocalizations that include repetitions of similar motifs. The multifactorial analysis showed that vocalizations of the Marquesan reed warblers differ slightly between species and that significant differences between islands led to different dialects. However, these dialects retained some common elements within each taxon, suggesting a phylogenetic component in the vocalization of Marquesan reed warblers. Differences in habitat richness, as broadly defined by the number of native plant species, were not significantly associated to their vocalization diversity. Marquesan reed warblers live in open habitats, which should have similar abiotic acoustic properties. This might have led to similar types of songs arising across the archipelago. In contrast, "continental" species of reed warblers vocalize from inside dense vegetation such as reed beds. The variation in their songs has been linked to differences in mating system and habitat quality (Leisler and SchulzeHagen 2011). In oscine passerines, males often learn singing behaviour from parental or neighbouring tutors, and elements inherited in this fashion should favour the evolution of local dialect (Wada 2010). In relatively small and isolated populations, the consequences of founder effects and of vocal drift have also been shown to favour the creation of local dialects, sometimes associated with a reduction of vocalization diversity compared to a larger source population (Valderrama et al. 2013), but not always (Baker et al. 2006).

\section{Conclusion}


In summary, the Marquesan reed warblers, two taxa that originated from independent lineages in the Pacific Ocean, exhibit convergent plumage colouration while retaining differences in songs. Vocal characteristics may act as the main pre-zygotic barriers when birds from different lineages come into contact. In a majority of passerines with a monogamous breeding strategy, dispersal is femalemediated (Greenwood 1980), as shown in migratory species (Guerrini et al. 2014) and in at least one insular situation (Paris et al. 2016). Although our data set was not designed to test sex-biased dispersal within the Marquesas archipelago, the occurrence of mitochondrial haplotype introgression is consistent with dispersal of at least one female between the two groups. Further work, in Nuku Hiva in particular, might be necessary to unravel the mechanisms in action in the contact zone between the two taxa. Until recently, mitochondrial DNA sequences and microsatellite loci (SSR, simple sequence repeats) were the gold standards in population genetics. Now, the use of genomic methods can provide hundreds or thousands of nuclear single-nucleotide polymorphisms (SNPs) generated by restriction-site associated DNA sequencing (RAD-seq), leading to a broader evaluation of the genome. While these new data set are not devoid of drawbacks, in particular related to evolutionary noise (Mesak et al. 2014), the study of the Marquesan reed-warblers would benefit from a genomic approach in the future.

\section{Acknowledgements}

We are very grateful to Joel Cracraft and Paul Sweet [American Museum of Natural History (AMNH), New York] for access to the collections in their charge and for the sampling of specimens. We thank Jean-Yves Meyer (Research Delegation, Tahiti), Claude Serra (DIREN Tahiti), Philippe Raust (Manu, Ornithological Society of Polynesia), Josie Lambourdière (MHNH), the Institut pour la Recherche et le Développement (Papeete), the Service du Développement Rural (Iles Marquises), and the Service de Systématique Moléculaire [UMS2700-CNRS, Muséum National d'Histoire Naturelle (MNHN), Paris]. Financial support by the Research Delegation (covenant $\left.n^{\circ} 5992 / M E E / R E C\right)$, the DIREN Tahiti and the 
Ornithological Society of Polynesia (covenant $n^{\circ} 6-0056 / m d d$ ), the Collection Study Grant from the Frank M. Chapman Memorial Fund (AMNH), the European Commission's Research Infrastructure Action via the SYNTHESYS Project (applications GB-TAF-1846/2002), the Systematic Research Fund of the Systematics Association and Linnean Society, the Swiss Academy of Sciences (Commission of travel grant), the G. and A. Claraz Foundation, the Basel Foundation for Biological Research, are gratefully acknowledged.

\section{References}

Alström, P., Olsson, U. and Lei, F. (2013). A review of the recent advances in the systematics of the avian superfamily Sylvioidea. Chinese Birds 4, 99-131.

Andersson, S. and Prager, M. (2006). Quantifying Colors. In 'Bird coloration: mechanisms and measurements'. (Eds G. E. Hill, G. E. Hill and K. J. McGraw) pp. 41-89. (Harvard University Press: Cambridge, Massachusetts.)

Baker, M. C., Baker, M. S. A. and Tilghman, L. M. (2006). Differing effects of isolation on evolution of bird songs: examples from an island-mainland comparison of three species. Biological Journal of the Linnean Society 89, 331-342.

Bandelt, H.-J., Forster, P. and Röhl, A. (1999). Median-joining networks for inferring intraspecific phylogenies. Molecular Biology and Evolution 16, 37-48.

Beerli, P. (2009). How to use migrate or why are markov chain monte carlo programs difficult to use? In 'Population Genetics for Animal Conservation, volume 17 of Conservation Biology, pages 42-79'. (Eds G. Bertorelle, M. W. Bruford, H. C. Haue, A. Rizzoli and C. Vernesi) pp. (Cambridge University Press: Cambridge UK.)

Bell, B. D. (2018). From wetlands to islands: morphological variation, plumage and song in Pacific island Acrocephalus warblers. Notornis 65, 202-222. 
Cibois, A., Beadell, J. S., Graves, G. R., Pasquet, E., Slikas, B., Sonsthagen, S., Thibault, J.-C. and Fleischer, R. C. (2011). Charting the course of reed-warblers across the Pacific islands. Journal of Biogeography 38, 1963-1975.

Cibois, A., Thibault, J.-C. and Pasquet, E. (2007). Uniform phenotype conceals double colonization by reed-warblers of a remote Pacific archipelago. Journal of Biogeography 34, 1150-1166.

Cibois, A., Thibault, J.-C. and Pasquet, E. (2008). Systematics of the extinct reed-warblers of the Society islands, Eastern Polynesia. The Ibis 150, 365-376.

Cibois, A., Thibault, J.-C. and Pasquet, E. (2010). Influence of Quaternary sea-level variations on a land bird endemic to Pacific atolls. Proceedings of the Royal Society of London B 277, 3445-3451.

Cibois, A., Thibault, J.-C. and Pasquet, E. (2012). The molecular basis of the plumage colour polymorphism in the Tahiti reed-warbler Acrocephalus caffer. Journal of Avian Biology 43, 38.

Diamond, J. M. (1974). Colonization of exploded volcanic islands by birds: The supertramp strategy. Science 184, 803-806.

Dieringer, D. and Schötterer, C. (2003). Microsatellite analyser (MSA): a platform independent analysis toll for large microsatellite data sets. Molecular Ecology Notes 3, 167-169.

Doutrelant, C., Paquet, M., Renoult, J. P., Grégoire, A., Crochet, P. A. and Covas, R. (2016). Worldwide patterns of bird colouration on islands. Ecology Letters 19, 537-545.

Ducrest, A.-L., Keller, L. and Roulin, A. (2008). Pleiotropy in the melanocortin system, coloration and behavioural syndromes. Trends in Ecology \& Evolution 23, 502-510.

Eaton, M. D. and Johnson, K. P. (2007). Avian visual perspective on plumage coloration confirms rarity of sexually monochromatic North American passerines. The Auk 124, 155-161.

Edwards, S. V., Arctander, P. and Wilson, A. C. (1991). Mitochondrial resolution of a deep branch in the genealogical tree for perching birds. Proceedings of the Royal Society of London B: Biological Sciences 243, 99-107. 
Evanno, G., Regnault, S. and Goudet, J. (2005). Detecting the number of clusters of individuals using the software STRUCTURE: a simulation study. Molecular Ecology 14, 2611-2620.

Excoffier, L., Laval, G. and Schneider, S. (2005). Arlequin ver. 3.1: An integrated software package for population genetics data analysis. Evolutionary Bioinformatics Online 1, 47-50.

Fiedler, B. (2011). Die Evolution des Gesanges der Acrocephalinae (Hippolais, Acrocephalus und Chloropeta) unter Einbeziehung der Phylogenie und morphologischer, ökologischer und sozialer Faktoren. Universität Oldenburg.

Fiedor, J. and Burda, K. (2014). Potential role of carotenoids as antioxidants in human health and disease. Nutrients 6, 466-488.

Fregin, S., Haase, M., Olsson, U. and Alström, P. (2009). Multi-locus phylogeny of the family Acrocephalidae (Aves: Passeriformes) - The traditional taxonomy overthrown. Molecular Phylogenetics and Evolution 52, 866-878.

Friedman, N. R., Kiere, L. M. and Omland, K. E. (2011). Convergent gains of red carotenoid-based coloration in the New World blackbirds. The Auk 128, 678-687.

Gangoso, L., Grande, J. M., Ducrest, A. L., Figuerola, J., Bortolotti, G. R., Andrés, J. A. and Roulin, A. (2011). MC1R-dependent, melanin-based colour polymorphism is associated with cellmediated response in the Eleonora's falcon. Journal of Evolutionary Biology 24, 2055-2063.

Gill, F. and Donsker, D. (2018). IOC World Bird List (v 8.2). doi : 10.14344/IOC.ML.8.2.

Goudet, J. (1995). FSTAT (Version 1.2): A Computer Program to Calculate F-Statistics. Journal of Heredity $86,485-486$.

Graves, G. R. (1992). The endemic land birds of Henderson Island, southeastern Polynesia: notes on natural history and conservation. Wilson Bulletin 104, 32-43.

Greenwood, P. J. (1980). Mating systems, philopatry and dispersal in birds and mammals. Animal Behaviour 28, 1140-1162.

Griffiths, R., Double, M. C., Orr, K. and Dawson, R. J. G. (1998). A DNA test to sex most birds. Molecular Ecology 7, 1071-1075. 
Guerrini, M., Gennai, C., Panayides, P., Crabtree, A., Zuberogoitia, I., Copland, A. S., Babushkina, O., Politi, P. M., Giunchi, D. and Barbanera, F. (2014). Large-Scale Patterns of Genetic Variation in a Female-Biased Dispersing Passerine: The Importance of Sex-Based Analyses. PLoS ONE 9, e98574.

Hofmann, C. M., Cronin, T. W. and Omland, K. E. (2006). Using spectral data to reconstruct evolutionary changes in coloration: carotenoid color evolution in New World orioles. Evolution 60, 1680-1691.

Jones, A. W. and Kennedy, R. S. (2008). Plumage convergence and evolutionary history of the Island Thrush in the Philippines. The Condor 110, 35-44.

Kearns, A. M., White, L. C., Austin, J. J. and Omland, K. E. (2015). Distinctiveness of Pacific Robin subspecies in Vanuatu revealed from disparate patterns of sexual dichromatism, plumage colouration, morphometrics and ancient DNA. Emu-Austral Ornithology 115, 89-98.

Kennerley, P. R. and Pearson, D. (2010). 'Reed and Bush Warblers'. (Christopher Helm: London.)

Kiere, L. M., Hofmann, C. M., Tracy, I. E., Cronin, T. W., Leips, J. and Omland, K. E. (2007). Using color to define species boundaries: Quantitative analysis in the Orchard Oriole complex supports the recognition of two species. The Condor 109, 692-697.

Komdeur, J., Piersma, T., Kraaijeveld, K., Kraaijeveld-Smit, F. and Richardson, D. S. (2004). Why Seychelles Warblers fail to recolonize nearby islands: unwilling or unable to fly there? Ibis 146, 298-302.

Leisler, B. and Schulze-Hagen, K. (2011). 'The Reed Warblers: Diversity in a Uniform Bird Family'. (KNNV Publishing: Zeist, The Netherlands.)

Leisler, B. and Winkler, H. (2015). Evolution of island warblers: beyond bills and masses. Journal of Avian Biology 46, 236-244.

Lemaire, F. (1977). Mixed song, interspecific competition and hybridisation in the reed and marsh warblers (Acrocephalus scirpaceus and palustris). Behaviour 63, 215-239. 
MacPherson, L. B. (1998). 'More birds of Polynesia' (CD). (McPherson Natural History Unit: Christchurch.)

Mallet, J., Besansky, N. and Hahn, M. W. (2016). How reticulated are species? BioEssays 38, 140-149.

Martens, J., Sun, Y.-H. and Päckert, M. (2008). Intraspecific differentiation of Sino-Himalayan bushdwelling Phylloscopus leaf warblers, with description of two new taxa. P. fuscatus, $P$. fuligiventer, P. affinis, P. armandii, P. subaffinis, 233-265.

Martin, P. R., Montgomerie, R. and Lougheed, S. C. (2010). Rapid sympatry explains greater color pattern divergence in high latitude birds. Evolution 64, 336-347.

Mason, N. A. and Taylor, S. A. (2015). Differentially expressed genes match bill morphology and plumage despite largely undifferentiated genomes in a Holarctic songbird. Molecular Ecology 24, 3009-3025.

McNaught, M. K. and Owens, I. P. F. (2002). Interspecific variation in plumage colour among birds: species recognition or light environment? Journal of Evolutionary Biology 15, 505-514.

Mesak, F., Tatarenkov, A., Earley, R.L., and Avise, J.C. (2014). Hundreds of SNPs vs. dozens of SSRs: which dataset better characterizes natural clonal lineages in a self-fertilizing fish? Frontiers in Ecology and Evolution 2, 74.

Montgomerie, R. (2006). Analyzing colors. In 'Bird coloration volume 1: mechanisms and measurements'. (Eds G. Hill and K. McGraw) pp. 90-147. (Harvard Univ. Press: Cambridge.)

Mosher, S. M. (2006). Ecology of the endangered Nightingale Reed-Warbler (Acrocephalus luscinia) on Saipan, Micronesia. Moscow, ID: University of Idaho.

Murphy, R. C. and Mathews, G. M. (1928). Birds collected during the Whitney South Sea Expedition. V. American Museum Novitates 337, 9-18.

Nosil, P. (2008). Speciation with gene flow could be common. Molecular Ecology 17, 2103-2106.

Ottenburghs, J., Ydenberg, R. C., Hooft, P. V., Wieren, S. E. V. and Prins, H. H. T. (2015). The Avian Hybrids Project: gathering the scientific literature on avian hybridization. Ibis 157, 892-894. 
Paris, D., Nicholls, A. O., Hall, A., Harvey, A. and Massaro, M. (2016). Female-biased dispersal in a spatially restricted endemic island bird. Behavioral Ecology and Sociobiology 70, 2061-2069.

Pfennig, D. W. and Pfennig, K. S. (2012). 'Evolution's wedge: competition and the origins of diversity'. (Univ of California Press:

Pillai, K. C. S. (1955). Some New test criteria in multivariate analysis. Ann. Math. Stat. 26, 117-121.

Poelstra, J. W., Vijay, N., Bossu, C. M., Lantz, H., Ryll, B., Müller, I., Baglione, V., Unneberg, P., Wikelski, M., Grabherr, M. G. and Wolf, J. B. W. (2014). The genomic landscape underlying phenotypic integrity in the face of gene flow in crows. Science 344, 1410-1414.

Potvin, D. A. and Clegg, S. M. (2015). The relative roles of cultural drift and acoustic adaptation in shaping syllable repertoires of island bird populations change with time since colonization. Evolution 69, 368-380.

Pritchard, J. K., Stephens, M. and Donnelly, P. (2000). Inference of population structure using multilocus genotype data. Genetics 155, 945-959.

R-Core-Team. (2017). R: A language and environment for statistical computing. R Foundation for Statistical Computing: Vienna, Austria. URL https://www.R-project.org/.

Reifová, R., Majerová, V., Reif, J., Ahola, M., Lindholm, A. and Procházka, P. (2016). Patterns of gene flow and selection across multiple species of Acrocephalus warblers: footprints of parallel selection on the Z chromosome. BMC Evolutionary Biology 16, 130.

Richardson, D. S., Jury, F. L., Dawson, D. A., Salgueiro, P., Komdeur, J. and Burke, T. (2000). Fifty Seychelles warblers (Acrocephalus sechellensis) microsatellite loci polymorphic in Sylviidae species and their cross-species amplification in other passerine birds. Molecular Ecology 9, 2155-2234.

Rousset, F. (1997). Genetic differentiation and estimation of gene flow from F-statistics under isolation-by-distance. . Genetics 145, 1219-1228. 
Rozas, J., Ferrer-Mata, A., Sánchez-DelBarrio, J. C., Guirao-Rico, S., Librado, P., Ramos-Onsins, S. E. and Sánchez-Gracia, A. (2017). DnaSP 6: DNA Sequence Polymorphism Analysis of Large Data Sets. Molecular Biology and Evolution 34, 3299-3302.

Saitoh, T., Cibois, A., Kobayashi, S., Pasquet, E. and Thibault, J.-C. (2012). The complex systematics of Acrocephalus of the Mariana Islands, western Pacific. The Emu - Austral Ornithology 112, 343-349.

Schneider, S. and Excoffier, L. (1999). Estimation of Past Demographic Parameters From the Distribution of Pairwise Differences When the Mutation Rates Vary Among Sites: Application to Human Mitochondrial DNA. Genetics 152, 1079-1089.

Sepp, T., Karu, U., Sild, E., Manniste, M. and Horak, P. (2011). Effects of carotenoids, immune activation and immune suppression on the intensity of chronic coccidiosis in greenfinches. Exp Parasitol 127, 651-7.

Tajima, F. (1989). Statistical method for testing the neutral mutation hypothesis by DNA polymorphism. Genetics 123, 585-595.

Thibault, J.-C. and Cibois, A. (2006). The natural history and conservation of Acrocephalus rimitarae, the endemic reed-warbler of Rimatara island, Oceania. Bulletin of the British Ornithological Club 126, 201-207.

Thibault, J. C. and Cibois, A. (2017). 'Birds of Eastern Polynesia. A biogeographic Atlas.'. (Lynx Edicions: Barcelona.)

Uy, J. A. C. and Vargas-Castro, L. E. (2015). Island size predicts the frequency of melanic birds in the color-polymorphic flycatcher Monarcha castaneiventris of the Solomon Islands. The Auk 132, 787-794.

Uy, J.A.C., Cooper, E.A., and Chaves, J.A. (2019). Convergent melanism in populations of a Solomon Island flycatcher is mediated by unique genetic mechanisms. Emu - Austral Ornithology, this issue. 
667 Valderrama, S. V., Molles, L. E. and Waas, J. R. (2013). Effects of Population Size on Singing Behavior 668 of a Rare Duetting Songbird. Conservation Biology 27, 210-218.

669 von Lintig, J. (2012). Metabolism of carotenoids and retinoids related to vision. The Journal of 670 biological chemistry 287, 1627-1634.

671 Wada, H. (2010). The Development of Birdsong. Nature Education Knowledge 3, 86.

672 Warren, B. H., Bermingham, E., Prys-Jones, R. P. and Thebaud, C. (2005). Tracking island colonization 673 history and phenotypic shifts in Indian Ocean bulbuls (Hypsipetes: Pycnonotidae). Biological $674 \quad$ Journal of the Linnean Society 85, 271-287.

675

676 
Fig.1
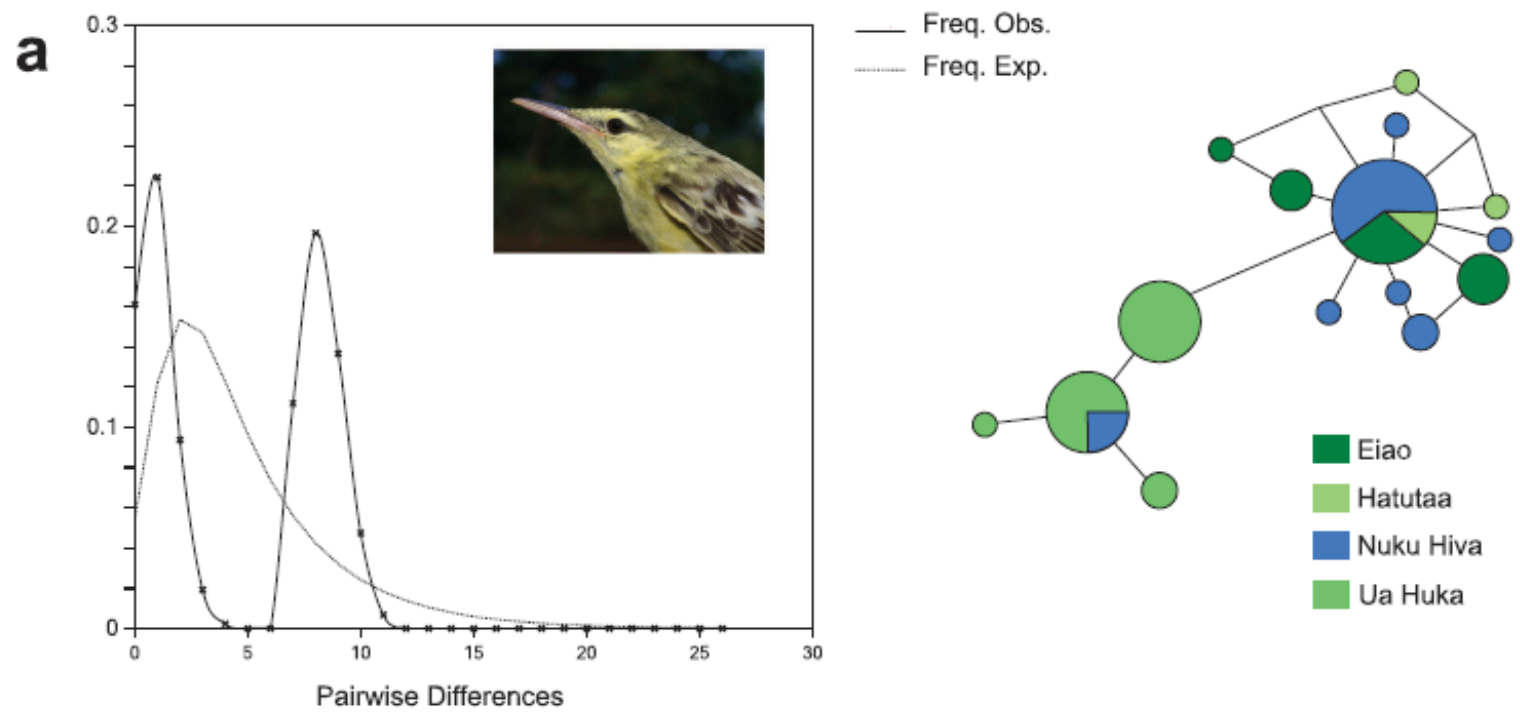

678
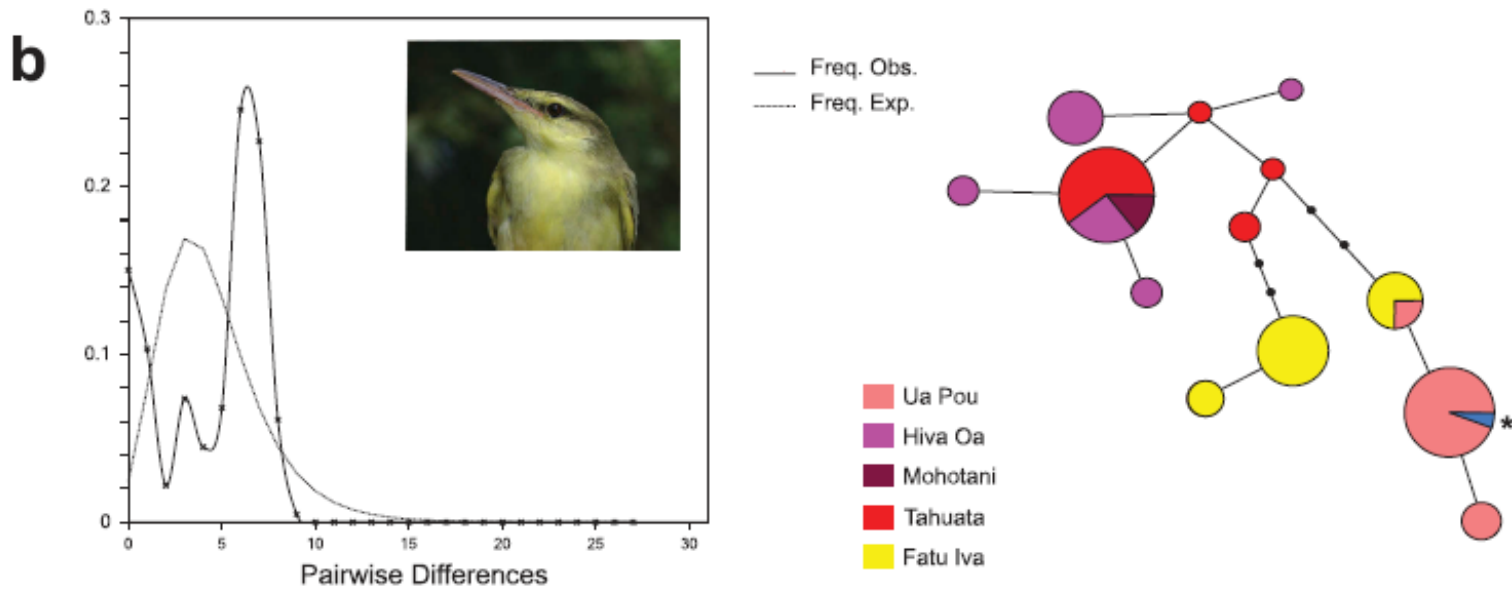

679 


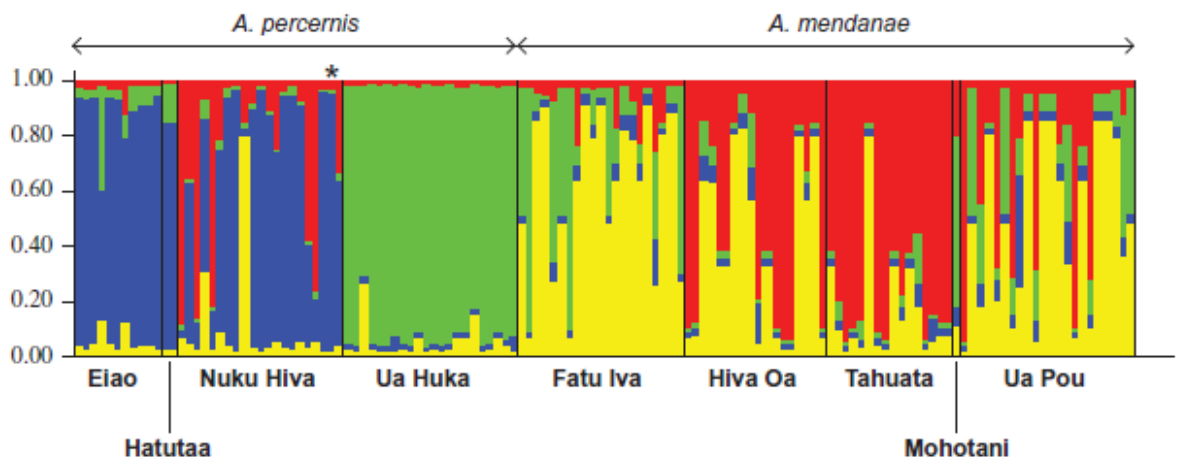

Figure 2. Individual barplots from each island corresponding to the optimal clusters $(K=4)$ found using an admixture model and the microsatellite loci in STRUCTURE (see online version for colour). The vertical lines each represent an individual, and colours represent the proportion of that individual assigned to each cluster. The asterisk indicates the individual sampled on Nuku Hiva (Nuku20) that presents a mitochondrial haplotype from the Southern group.

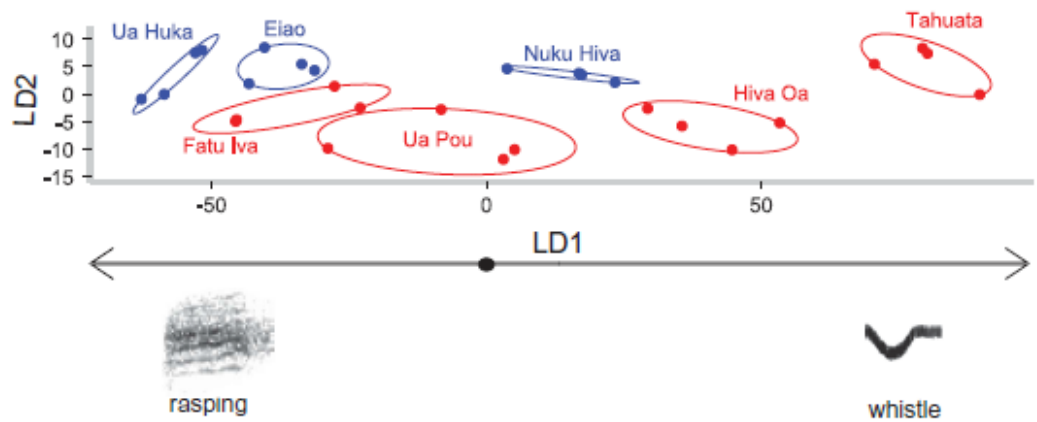


